\title{
HUBUNGAN KEBIASAAN MEROKOK DAN BEBAN KERJA FISIK DENGAN HIPERTENSI PADA PEKERJA LAKI-LAKI DI AREA PRODUKSI PT PUTRA BUNGSU TEGAL
}

\author{
Siti Dewi Ismayatun \\ Keselamatan dan Kesehatan Kerja, Universitas Airlangga \\ Surabaya. Email: Ismayadewi29@gmail.com
}

\begin{abstract}
Hypertension is influenced by several factors, one of which is life habits. Smoking has become a habit for most people, especially men in Indonesia. Cigarettes contain more than 600 kinds of toxic compounds that are harmful to the body. Three main substances in cigarettes are tar, nicotine and CO. These three toxic substances cause an increase in blood pressure. This study used a cross sectional study design. The sample in this study were 38 workers in the production area of PT Putra Bungsu Tegal selected from the population by simple random sampling technique. The results showed that there was a significant relationship between physical workload and hypertension $(p=0.019)$, but not with smoking habits $(p=0.653)$. The conclusion of this study was that there was a relationship between physical workload and hypertension. The company should do work rotation on workers who have a heavy workload and review the workload given whether it is in accordance with the ability of workers.
\end{abstract}

Keywords: Smoking habits, physical workload, hypertension

\begin{abstract}
ABSTRAK
Hipertensi dipengaruhi oleh beberapa faktor, salah satunya adalah kebiasaan hidup. Merokok telah menjadi kebiasaan bagi sebagian besar masyarkat khususnya laki-laki di Indonesia. Rokok mengandung lebih dari 600 macam senyawan beracun yang berbahaya bagi tubuh. Tiga zat utama yang ada dalam rokok yaitu tar, nikotin dan CO. Ketiga zat toksik tersebut menyebabkan terjadinya peningkatan tekanan darah. Penelitian ini menggunakan desain studi cross sectional. Sampel dalam penelitian ini sebanyak 38 pekerja di area produksi PT Putra Bungsu Tegal yang dipilih dari populasi dengan teknik simple random sampling. Hasil penelitian menunjukan ada hubungan yang bermakna antara beban kerja fisik dengan hipertensi $(\mathrm{p}=0,019)$, namun tidak dengan kebiasaan merokok $(\mathrm{p}=$ 0,653). Kesimpulan dari penelitian ini adalah ada hubungan antara beban kerja fisik dengan hipertensi. Perusahaan sebaiknya melakukan rotasi kerja pada pekerja yang memiliki beban kerja berat dan meninjau beban kerja yang diberikan apakah sesuai dengan kemampuan pekerja.
\end{abstract}

Kata kunci: Kebiasaan merokok, beban kerja fisik, hipertensi

\section{PENDAHULUAN}

Undang-Undang Dasar 1945 mengamanatkan bahwa kesehatan merupakan hak asasi manusia, yang artinya kesehatan merupakan hal yang dapat dirasakan oleh setiap orang. UndangUndang nomor 36 tahun 2009 tentang kesehatan 
juga mendefinisikan bahwa kesehatan adalah keadaan sejahtera dari badan, jiwa, dan sosial yang memungkinkan setiap orang hidup produktif secara sosial dan ekonomi. Sehat tentunya menjadi menjadi hal yang diharapkan setiap orang, namun masih banyak permasalahan kesehatan yang sering ditemui.

Hipertensi masih menjadi permasalah yang sering ditemukan di Indonesia. World Health Organization (WHO) tahun 2011 menyatakan bahwa satu milyar orang di dunia khususnya di negara berkembang mengalami hipertensi. 1/3 dari 1,5 juta kematian penduduk di asia tenggara disebabkan oleh hipertensi.

Hipertensi adalah meningkatnya tekanan darah sistolik lebih dari $140 \mathrm{mmHg}$ dan diastolik lebih dari $90 \mathrm{mmHg} .{ }^{1}$ Hal tersebut terjadi karena jantung memompa lebih keras guna memenuhi kebutuhan nutrisi dan oksigen tubuh. Tekanan darah yang semakin meninggi, menyebabkan jantung harus memompa darah secara lebih aktif. Jika keadaan seperti ini dibiarkan secara terus menerus dan tidak dilakukan upaya pencegahan sejak dini dapat menyebabkan jantung menjadi lemah yang berakibat pada terjadinya gagal jantung. Tekanan darah tinggi juga mengakibatkan adanya kerusakan pada organ-organ vital manusia seperti otak, dan ginjal. $^{2}$

Hipertensi dipengaruhi oleh beberapa faktor, seperti pola hidup, beban kerja dll. Merokok telah menjadi kebiasaan dalam pola hidup sebagian besar masyarkat khususnya laki- laki di Indonesia. Data Riset Kesehatan Dasar menunjukan prevalensi perokok usia diatas 15 mengalami peningkatan setiap tahunnya, jumlah pada tahun 2007 sebanyak 34,7\% dan meningkat menjadi $36,3 \%$ pada tahun $2013 .^{3}$

Rokok mengandung lebih dari 600 macam senyawan beracun yang berbahaya bagi tubuh. ${ }^{4}$ Tiga zat utama yang ada dalam rokok yaitu tar, nikotin dan CO. Ketiga zat toksik tersebut menimbulkan terjadinya peningkatan tekanan darah. Nikotin merangsang pengeluaran hormon epinefrin dan norepinefrin yang menyebabkan vasokontriksi pada pembuluh darah, sehingga jantung terpacu untuk bekerja lebih keras dan terjadilah kenaikan tekanan darah. Karbonmonoksida (CO) mempercepat terjadinya penumpukan plak pada dinding pembuluh darah (arterosklerosis). Plak inilah yang menyebabkan sumbatan pada pembuluh darah sehingga tekanan pada pembuluh darah meningkat.

Penelitian yang dilakukan oleh Badan Litbang Kemenkes tahun 2010 menunjukan bahwa penyakit yang terkait dengan tembakau menyumbang kematian sekitar $190.260(12,7 \%)$ orang dari total kematian di tahun 2010. ${ }^{5}$

Beban kerja fisik juga merupakan salah satu faktor yang menyebabkan peningkatan tekanan darah dikarenakan semakin berat beban kerja maka tubuh semakin banyak membutuhkan energi dan supply oksigen, oleh sebab itu jantung memompa lebih keras untuk memenuhi tuntutan tersebut sehingga tekanan darah menjadi meningkat. 
Hasil wawancara dengan pekerja dan manager operasional di PT Putra Bungsu Tegal didapatkan hasil bahwa pekerja sering merasakan sakit kepala dan persediaan obat sakit kepala di kotak P3K sering habis. William PB dan Palmer menyatakan salah satu gejala yang timbul pada orang yang mengalami kenaikan tekanan darah adalah sakit kepala (pusing). ${ }^{6}$

Tujuan penelitian adalah menganalisis hubungan kebiasaan merokok dengan hipertensi pada pekerja laki-laki di area produksi PT Puta Bungsu Tegal.

\section{METODE PENELITIAN}

Penelitian ini termasuk kedalam penelitian lapangan karena langsung dilakukan di tempat kerja. Jenis rancangan penelitian ini adalah observasional analitik dikarenakan data yang diperoleh didapatkan tanpa adanya perlakuan terhadap objek penelitian. Berdasar-kan segi waktu, Penelitian ini menggunakan desain studi cross sectional dikarenakan variabel yang diukur diambil dalam satu waktu.

Sampel penelitian ini adalah pekerja di area produksi PT putra Bungsu Tegal. Sampel penelitian diambil menggunakan teknik simple random sampling dan diperoleh sampel sebanyak 38 responden.

Penelitian ini dilakukan pada pekerja di area produksi PT Putra Bungsu Tegal pada bulan Agustus 2018. Data dalam penelitian ini diperoleh dari kuesioner yang disebarkan pada pekerja dan berdasarkan hasil pengukuran tekanan darah.

Variabel independen adalah kebiasaan merokok, dan variabel dependennya adalah hipertensi. Variabel independen terdiri dari status merokok, jenis rokok dan jumlah rokok yang dihabiskan dalam sehari. Data yang telah diperoleh dari hasil penelitian disajikan dalam bentuk deskriptif dan dianalisa secara statistik dengan uji “Fisher's Exact Test” untuk mengetahui hubungan kebiasaan merokok dengan hipertensi. Dikatakan ada hubungan jika didapatkan nilai $p$-value $<0,05$.

\section{HASIL DAN PEMBAHASAN}

Kebiasaan merokok terdiri dari status merokok, jenis rokok yang dikonsumsi, dan jumlah rokok yang dikonsumsi pekerja dalam satu hari. Status merokok dibagi dalam dua kategori yaitu merokok dan tidak merokok.

\section{Usia Responden dengan Hipertensi pada Pekerja}

Tabel 1. Tabulasi Silang Usia Responden dengan Hipertensi pada Pekerja

\begin{tabular}{|c|c|c|c|c|c|c|c|c|}
\hline & \multirow[t]{3}{*}{ Usia } & \multicolumn{4}{|c|}{ Hipertensi } & \multirow{2}{*}{\multicolumn{2}{|c|}{ Total }} & \multirow[t]{3}{*}{ p-value } \\
\hline & & \multicolumn{2}{|c|}{ Ya } & \multicolumn{2}{|c|}{ Tidak } & & & \\
\hline & & $\mathrm{n}$ & $\%$ & $\mathrm{n}$ & $\%$ & $\mathrm{n}$ & $\%$ & \\
\hline 1. & $\leq 25$ tahun & 1 & 10,0 & 9 & 90,0 & 10 & 100,0 & 0,653 \\
\hline 2. & $>25$ tahun & 7 & 25,0 & 21 & 75,0 & 28 & 100,0 & \\
\hline & Total & 8 & 21,1 & 30 & 78,9 & 38 & 100,0 & \\
\hline
\end{tabular}


Berdasarkan tabel diatas dapat diketahui bahwa pekerja dengan usia diatas 25 tahun lebih banyak mengalami hipertensi dibanding pekerja yang berusia kurang dari 25 tahun, namun jumlah pekerja yang tidak hipertensi jauh lebih banyak dari pekerja yang hipertensi.

Berdasarkan hasil uji Fisher's Exact Test ( $\mathrm{p}=0,653$ ) nilai $p$-value $<0,05$ yang artinya bahwa usia tidak ada hubungan antara usia dengan hipertensi pada pekerja di area produksi PT Putra Bungsu Tegal.

Dalam penelitian ini, hipertensi yang terjadi pada pekerja bukan disebabkan oleh faktor usia. Faktor lain yang mungkin menyebabkan hipertensi pada pekerja di PT Putra Bungsu Tegal adalah faktor lingkungan fisik di tempat kerja, area produksi merupakan tempat yang menghasilkan bising. Paparan bising dapat menimbulkan reaksi fisiologis yang salah satunya peningkatan tekanan darah.

Tidak adanya hubungan yang bermakna antara usia dengan hipertensi mungkin juga disebabkan oleh pola hidup sehat yang dilakukan oleh responden, sehinga meskipun berusia diatas 25 tahun tekanan darahnya masih dalam batas normal.

\section{Status Merokok Responden dengan Hipertensi pada Pekerja}

Tabel 2. Tabulasi Silang Status Merokok dengan Hipertensi Pada Pekerja

\begin{tabular}{|c|c|c|c|c|c|c|c|c|}
\hline \multirow[t]{3}{*}{ No } & \multirow[t]{3}{*}{ Status merokok } & \multicolumn{4}{|c|}{ Hipertensi } & \multirow{2}{*}{\multicolumn{2}{|c|}{ Total }} & \multirow[t]{3}{*}{$p$-value } \\
\hline & & \multicolumn{2}{|c|}{$\mathrm{Ya}$} & \multicolumn{2}{|c|}{ Tidak } & & & \\
\hline & & $\mathrm{n}$ & $\%$ & $\mathrm{n}$ & $\%$ & $\mathrm{n}$ & $\%$ & \\
\hline 1. & Merokok & 4 & 26,7 & 11 & 73,3 & 15 & 100,0 & \\
\hline 2. & Tidak merokok & 4 & 17,4 & 19 & 82,6 & 23 & 100,0 & 0,687 \\
\hline & Total & 8 & 21,1 & 30 & 78,9 & 38 & 100,0 & \\
\hline
\end{tabular}

Berdasarkan Tabel 2. di atas menunjukkan bahwa persentase pekerja yang tidak merokok cenderung memiliki riwayat hipertensi lebih tinggi $(82,6 \%)$ dibandingkan dengan pekerja yang merokok $(73,3 \%)$.

Berdasarkan hasil uji Fisher's Exact Test didapatkan nilai signifikansi $(p$-value $)=0,687$ $<0,05$ yang artinya bahwa tidak ada hubungan yang signifikan antara merokok dengan hipertensi pada pekerja di area produksi PT Putra Bungsu Tegal.
Zat yang terdapat dalam rokok menyebabkan adanya plak yang menyumbat lapisan dinding pembuluh darah arteri, sumbatan ini menyebabkan tekanan pada pembuluh darah meningkat. Nikotin dalam rokok menyebabkan adanya rangsangan hormon epinefrin atau hormon adrenalin yang bersifat memacu peningkatan frekuensi denyut jantung, tekanan darah. $^{7}$

Hasil penelitian yang telah dilakukan di PT Putra Bungsu tegal tidak senada dengan teori 
diatas, namun sesuai dengan hasil penelitian yang dilakukan olej Li guoju, Wang hailing, Wang ke tahun 2017 yang menyatakan bahwa tidak terdapat hubungan bermakna antara merokok dengan tekanan darah. ${ }^{8}$ penelitian tersebut mendapati bahwa peningkatan tekanan darah pada perokok lebih rendah dari responden yang merokok.

Tidak adanya hubungan antara merokok dengan hipertensi pada penelitian ini dapat disebabkan oleh beberapa hal, seperti gaya hidup responden. Responden pada penelitian ini bekerja mengandalkan kekuatan fisik. Aktivitas fisik dapat menurunkan risiko hipertensi dengan menekan aktivitas dari sistem reninangiotensin dan sistem saraf simpatik serta mengurangi resistensi pembuluh darah. ${ }^{9}$

Makanan yang dikonsumsi responden juga dapat menjadi salah satu faktor tidak terjadi kenaikan tekanan darah pada perokok. Kandungan kalium dalam pisang dapat menghilangkan pengaruh nikotin dalam tubuh. ${ }^{10}$
Responden yang termasuk kedalam status merokok namun tidak hipertensi mungkin saja rutin mengkonsumsi pisang atau makanan lain yang dapat menurunkan tekanan darah seperti timun, alpukat dll.

\section{Jenis Rokok}

Kadar nikotin yang diserap dalam tubuh seseorang berbeda-beda. Selain dilihat dari jumlah rokok yang dikonsumsi, jenis rokok juga dapat menentukan kadar niktoin yang masuk kedalam tubuh. Jenis rokok terdiri dari dua macam, yaitu memiliki filter dan yang tidak memiliki filter (non-filter). Kandungan nikotin dalam rokok non filter lebih banyak dikarenakan tidak adanya penyaring untuk mengurangi tar dan nikotin pada rokok yang dihisap.

Tidak ditemukan variasi jenis rokok yang dikonsumsi responden dikarenakan seluruh pekerja di PT Putra Bungsu Tegal mengkonsumsi rokok berfilter, sehingga tidak dapat dilakukan analisis hubungan jenis rokok dengan hipertensi.

\section{Jumlah Rokok yang Dikonsumsi Responden dalam Sehari dengan Hipertensi}

Tabel 3. Tabulasi Silang Jumlah Rokok dengan Hipertensi Pada Pekerja

\begin{tabular}{|c|c|c|c|c|c|c|c|c|}
\hline \multirow[t]{3}{*}{ No } & \multirow{3}{*}{$\begin{array}{l}\text { Jumlah rokok yang dikonsumsi } \\
\text { dalam sehari }\end{array}$} & \multicolumn{4}{|c|}{ Hipertensi } & \multirow{2}{*}{\multicolumn{2}{|c|}{ Total }} & \multirow[t]{3}{*}{$p$-value } \\
\hline & & \multicolumn{2}{|c|}{$\mathrm{Ya}$} & \multicolumn{2}{|c|}{ Tidak } & & & \\
\hline & & $\mathrm{n}$ & $\%$ & $\mathrm{n}$ & $\%$ & $\mathrm{n}$ & $\%$ & \\
\hline 1. & $<10$ batang & 2 & 20,0 & 8 & 80,0 & 10 & 100,0 & \multirow{3}{*}{0,560} \\
\hline \multirow[t]{2}{*}{2.} & $\geq 10$ batang & 2 & 40,0 & 3 & 60,0 & 5 & 100,0 & \\
\hline & Total & 4 & 26,7 & 11 & 73,3 & 15 & 100,0 & \\
\hline
\end{tabular}

Tabel diatas menunjukkan jumlah pekerja yang tidak mengalami hipertensi lebih banyak dibandingkan yang mengalami hipertensi. Data di atas juga menunjukkan pekerja yang mengkonsumsi rokok lebih dari 10 batang perhari memiliki presentasi hipertensi lebih tinggi. 
Berdasarkan hasil uji Fisher's Exact Test ( $\mathrm{p}=0,560)$ menunjukan bahwa ada hubungan yang bermakna antara jumlah rokok yang dikonsumsi dalam satu hari dengan hipertensi pada pekerja.

Ketidaksesuaian teori diatas mungkin disebabkan adanya responden yang tidak mampu mengingat jumlah pasti rokok yang biasa dihabiskan dalam satu hari. Hasil penelitian ini sesuai dengan penelitian yang dilakukan oleh Li Hongmei, Tong Weijun, dan Wng Aili tahun 2010 yang menyatakan bahwa tidak ada hubungan antara merokok dengan hipertensi. ${ }^{11}$ Responden yang menghabiskan rokok 1-9 batang, 10-19 batang, dan > 20 batang perhari memiliki tekanan darah lebih rendah dibandingkan dengan responden yang tidak merokok.

\section{Beban Kerja Responden dengan Hipertensi pada Pekerja}

Tabel 4. Tabulasi Silang Beban Kerja dengan Hipertensi Pada Pekerja

\begin{tabular}{|c|c|c|c|c|c|c|c|c|}
\hline \multirow[t]{3}{*}{ No } & \multirow[t]{3}{*}{ Beban Kerja } & \multicolumn{4}{|c|}{ Hipertensi } & \multirow{2}{*}{\multicolumn{2}{|c|}{ Total }} & \multirow[t]{3}{*}{$p$-value } \\
\hline & & \multicolumn{2}{|c|}{$\mathrm{Ya}$} & \multicolumn{2}{|c|}{ Tidak } & & & \\
\hline & & $\mathrm{n}$ & $\%$ & $\mathrm{n}$ & $\%$ & $\mathrm{n}$ & $\%$ & \\
\hline 1. & Ringan & 0 & 0,00 & 0 & 0,00 & 0 & 0,00 & \\
\hline 2. & Sedang & 3 & 10,7 & 25 & 89,3 & 28 & 100,0 & 0,019 \\
\hline 3. & Berat & 5 & 50,0 & 5 & 50,0 & 10 & 100,0 & \\
\hline & Total & 8 & 21,1 & 30 & 78,9 & 38 & 100,0 & \\
\hline
\end{tabular}

Tabel diatas menunjukan bahwa jumlah pekerja yang tidak mengalami hipertensi lebih banyak dibanding pekerja yang mengalami hipertensi. Data diatas juga menunjukan bahwa seluruh pekerja yang memiliki beban kerja berat mengalami hipertensi.

Berdasarkan hasil uji Fisher's Exact Test $(\mathrm{p}=0,019)$ nilai $p$-value $<0,05$ yang artinya bahwa ada hubungan yang bermakna antara beban kerja dengan hipertensi pada pekerja di area produksi PT Putra Bungsu Tegal.

Hasil penelitian di PT Putra Bungsu sesuai dengan hasil penelitian yang dilakukan oleh Sinubu RS, Rondonuwu R, Onibala F pada tahun 2015 yang menyatakan terdapat hubungan beban kerja dengan kejadian hipertensi pada tenaga pengajar di SMAN 1 Amurang Kabupaten Minahasa Selatan $(\mathrm{p}=0,023) .{ }^{12}$

\section{SIMPULAN DAN SARAN \\ Simpulan}

Berdasarkan hasil uji statistik dapat disimpulkan bahwa ada hubungan antara beban kerja fisik dengan hipertensi. Akan tetapi, tidak terdapat hubungan bermakna antara kebiasaan merokok dengan hipertensi pada pekerja lakilaki di area produksi PT Putra Bungsu Tegal.

\section{Saran}

Saran yang dapat diberikan adalah perusahaan sebaiknya melakukan rotasi kerja 
pada pekerja yang memiliki beban kerja berat dan meninjau beban kerja yang diberikan apakah sesuai dengan kemampuan pekerja. Perusahaan juga harus menyediakan ruang khusus untuk merokok agar paparan asap rokok tidak dihirup oleh pekerja lain khususnya yang tidak merokok. Penyediaan ruang khusus merokok juga berfungsi untuk mencegah terjadinya kebakaran di tempat kerja yang disebabkan oleh bara api rokok. Bagi pekerja sebaiknya diberikan edukasi mengenai bahaya merokok dan pola hidup sehat agar mampu mencegah hipertensi. Bagi peneliti selanjutnya perlu dilakukan penelitian lebih lanjut mengenai faktor-faktor lain yang mempengaruhi hipertensi.

\section{REFERENSI}

1. Bradero, M., Dayrit, M.W. dan Siswadi, Y. Seri Asuhan Keperawatan Klien Gangguan Kardiovaskuler. Jakarta. EGC. 2008.

2. Ridwan. Mengenal, Mencegah, Hipertensi, Mengatasi Silent Killer Hipertensi. Semarang. Pustaka Widyamara. 2009.

3. Balitbang Kemenkes RI. Riset Kesehatan Dasar; RISKESDAS. Jakarta. Balitbang Kemenkes RI. 2013.

4. Lingga, L., Bebas Hipertensi Tanpa Obat. Jakarta Selatan. PT AgroMedia Pustaka. 2012.
5. Balitbang Kemenkes RI. Riset Kesehatan Dasar; RISKESDAS. Jakarta. Balitbang Kemenkes RI. 2010.

6. Palmer, A. dan William, B. Simple Guide Tekanan Darah Tinggi. Jakarta. Erlangga. 2007.

7. Aula, L.E. Stop Merokok. Jogjakarta. Garailmu. 2010.

8. Li Guoju, Wang Hailing, Wang Ke. The Association between Smoking and Blood Pressure in Men: A Cross Sectional Study. BMC Public. 2017. https://www.ncbi.nlm.nih.gov/pmc/articles/P MC5634904/

9. Cheng S, Yu H, Chen C. Physical Activity and Risk of Cardiovascular Disease among Older Adults. International Journal of Gerontology. 7(3), 133-136. 2013.

10. Suyanti dan Supriyadi, A. Pisang, Budi Daya, Pengolahan, dan Prospek Pasar. Jakarta. Penebar Swadaya. 2008.

11. Li Hongmeli, Tong Weijun, Wang Aili. Effects of Cigarette Smoking on Blood Pressure Stratified by BMI in Mongolian Population, China. PubMed. 2010. DOI: $10.3109 / 08037050903516300$.

https://www.researchgate.net/publication/4 1011676_Effects_of_cigarette_smoking_o n_blood_pressure_stratified_by_BMI_in_ Mongolian_population_China

12. Sinubu, RS., Randonuwu, R., Onibala, F. Hubungan Beban Kerja dengan Hipertensi pada Pengajar di SMAN 1 Amurang Kabupaten Minahasa Selatan. Jurnal Keperawatan vol 3. No 2. 2015. https://ejournal.unsrat.ac.id/index.php/jkp/a rticle/view/8034 